\title{
Procrastination and its effect on English writing errors and writing performance of medical students
}

\author{
Reza Kafipour ${ }^{1 *}$ and Samaneh Jafari ${ }^{2}$ \\ ${ }^{1}$ English Department, School of Paramedical Sciences, Shiraz University of Medical Sciences, Shiraz, Iran, Zip \\ code 7143914693 \\ ${ }^{2}$ Department of Curriculum and Instruction, Southern Illinois University Carbondale 1263 Lincoln Dr, \\ Carbondale, IL 62901, United States of America
}

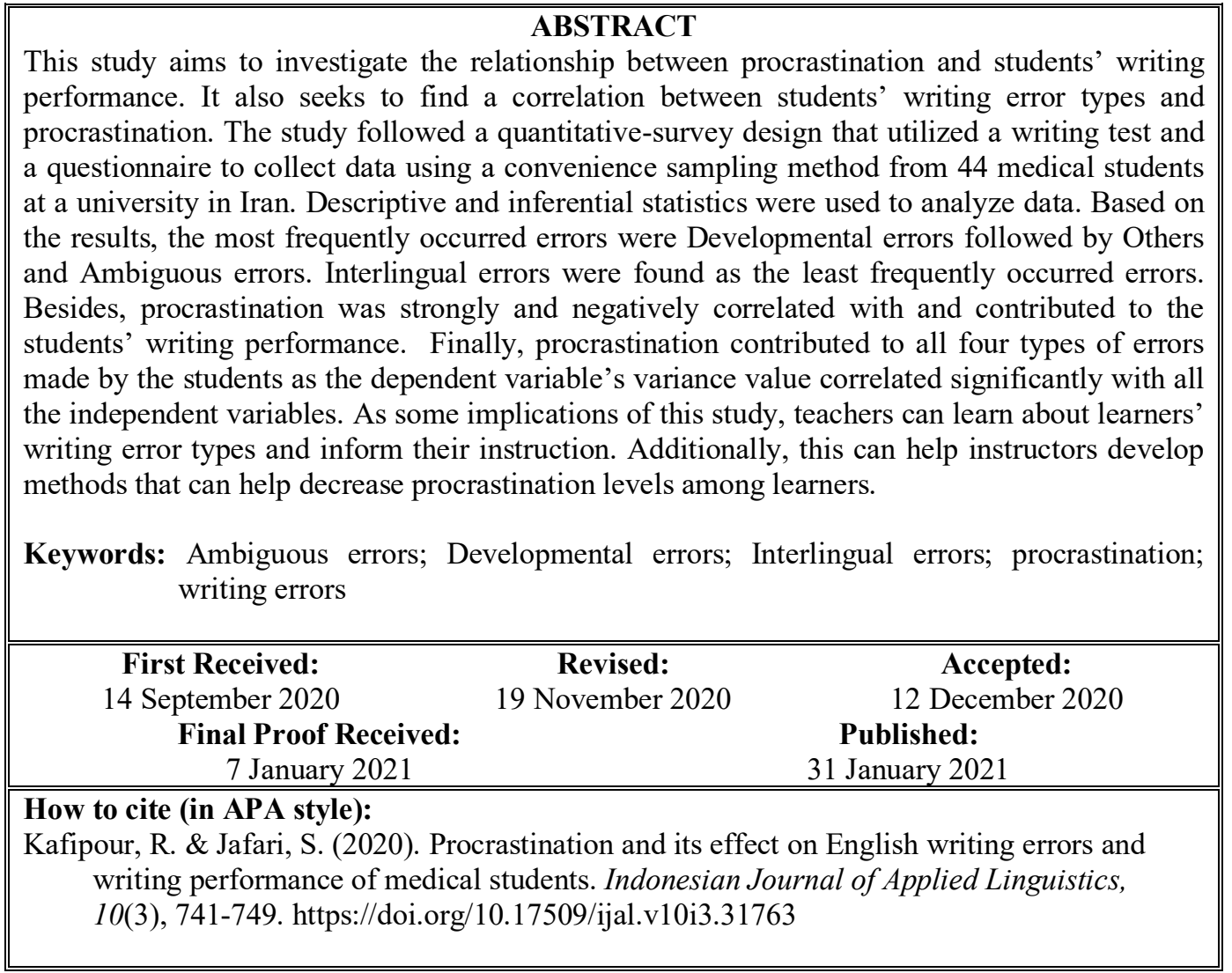

\section{INTRODUCTION}

Inspite of being one of the significant skills, writing is deemed as one of the most complex and multiplex skills to be mastered (Khakpour-Nia \& Shahsavar, 2019). Nowadays, major teaching and learning approaches are becoming increasingly learnercentered; hence, scrutiny into factors which affect learners' performance opens new horizons to researchers in the field of language learning and teaching. Students' procrastination is among the aforementioned factors that may affect the writing performance.

As a variable of the current study, procrastination is defined as postponing an action

*Corresponding Author

Email: rezakafipour@gmail.com despite being aware of the negative effects and outcomes of such postponing or doing the action at the very last minute (Babadoğan, 2010). Schouwenburg (1995) found in his study that $70 \%$ of the participants reported procrastinating on a regular basis while $20 \%$ reported procrastinating as a habit. Given that universities and academic institutions in Iran ask the students to complete their tasks, whether studying for exams or delivering their homework and classwork, the procrastinating students may perform poorly in comparison with those who tend to do assignments on time.

Academic procrastination is a major challenge for many graduate and postgraduate students in 
exam-oriented educational systems such as the one functioning in Iran. In Iran, most students are judged and evaluated solely through exams in general and are overloaded with examinations, term papers, and projects during the course of their academic careers. The same transpires in English writing exams as well. The students intentionally do their homework and classwork beyond a reasonable period of time. Sometimes they may even study for exams at the last minute. All these activities in delaying the task lead to stress, anxiety, and academic procrastination (Steel, 2007).

Academic procrastination is related to lower levels of self-regulation, academic self-efficacy, and self-esteem, and is associated with higher levels of anxiety, stress, and illness (e.g. Ferrari et al., 2005; Howell et al., 2006; Schraw et al., 2007; Tice \& Baumeister, 1997; Wolters, 2003). Steel (2007) noted strong and consistent predictors of procrastination to be "task delay, self-efficacy, impulsiveness as well as conscientiousness and examples of its facets being self-control, distractibility, organization, and achievement motivation" (p. 65). The high level of academic procrastination by the students can have detrimental effects on students' psychological well-being and their academic performance (Kim et al., 2017; Kim, \& Seo, 2015; Schraw et al., 2007; Shokeen, 2018). Estimates by different researchers indicate that 80 $95 \%$ of college students (O'Brien, 2002) or at least $50 \%$ of the students (Ozer et al., 2009; Solomon \& Rothblum, 1984) engage in procrastination, and the prevalence of the phenomenon appears to be growing (Steel, 2007). Writing is among those skills which are highly affected by academic procrastination.

There are different reasons that students procrastinate in their writing tasks. Based on Gray (2017), one reason students procrastinate on their writing assignments is lack of engagement with the topic. The students procrastinate if they do not have an interest or a wide variety of choices on topic or writing format. Over $50 \%$ of students mentioned that they fear the task of writing (Onwuegbuzie, \& Collins, 2001; Fritzsche et al., 2003) and if they have a lot of time before the deadline, there is a high chance that they will procrastinate since there is no reason to start the task early. Insufficient writing skills in English, time constraints, and fear of negative comments were shown to be other aspects of procrastination in writing (Ho, 2016). Setting an earlier deadline and discussing the work before the deadline are other alternatives that can mitigate the procrastination outcomes (Fritzsche et al., 2003).

Perry (2012) believes that procrastinator rarely is idle and procrastination is not always negative; that is, the procrastinator just does not like to be forced to do specific activities. Some other reasons may be low frustration tolerance (Harrington, 2005), and performance anxiety (Seo, 2008). Moreover,
Chow (2011) found that students with lower socioeconomic status procrastinated more while Gropel and Steel (2008) found out that younger students procrastinated more than older students. Even lack of a conductive workplace was identified by Pigg (2014) as another cause for procrastination. Stewart et al. (2016) mentioned insufficient selfregulation as one of the other causes for procrastination since it leads to different negative study performance.

As it was elaborated before, students' procrastination may be one of the factors that affect their writing performance, leading to writing errors. Therefore, it is important to know what kinds of writing errors are quite dominant as students learn the target language. In this case, an analysis of the errors is very beneficial. Error Analysis is the process of determining the incidence, nature, causes, and consequences of unsuccessful language (James, 1998). Based on Dulay et al. (1982), errors made by language learners are very important in order to help identify the process of language acquisition/learning. Errors can be analyzed to find effective strategies to prevent learners from repeating errors and to inform teachers for an effective form of instruction.

In order to identify the errors made by L2 learners, the comparative taxonomy of Dulay et al. (1982) has been used in this study. Comparative refers to "comparisons between the structure of L2 errors and certain other types of constructions" (Dulay et al., 1982, p. 163). Four error categories are included in this taxonomy: Developmental, Interlingual, Ambiguous and Other errors. Developmental errors are similar to the kinds of errors made by children when they learn the target language as their first language. Interlingual errors are made when a sentence or phrase has the same or similar structure to the ones in the learner's native language. Ambiguous errors are the ones that can be classified equally to Developmental or Interlingual categories. Finally, Other errors are those which do not belong to any of the categories mentioned.

This study highlights if there is a significant relationship between writing errors and students' procrastination levels. To sum up, the purpose of the present study is to investigate whether having a higher level of academic procrastination has a significant influence on writing performance and writing errors of EFL learners. This study seeks to find answers to the following research questions:

1. What are the different types of errors found in students' English writing based on Dulay et al. (1982) classification system?

2. Does procrastination correlate with and contribute to the students' writing performance? 
3. Does procrastination correlate with and contribute to the types of errors committed by students?

\section{METHOD \\ Design}

The study followed a quantitative-survey design. In order to collect data, a writing test and a questionnaire were used.

\section{Participants}

The study was conducted at Shiraz University of Medical Sciences. All available 44 medical students who had a compulsory English writing course in second semester 2016 were selected through convenience sampling method and participated in this study; therefore, 44 is the overall population of students who had a writing course at the time when the study was conducted. They were 30 females and 14 males.

\section{Instrument}

The questionnaire used in the current study was the abbreviated Procrastination Assessment Scale (PASS), a 5-item Likert scale questionnaire, originally developed by Solomon and Rothblum (1984) and adapted from Kong (2010). It is a popular and widely used questionnaire. To ensure thorough comprehension of the items in the questionnaire, the researchers translated the questionnaire into Persian and tested the content validity of PASS questionnaire by asking three TEFL experts to check the items available in the translated version. The changes suggested by these experts involving edition, deletion, or addition were applied in preparing the final version of the questionnaire. The reliability of the questionnaire was also tested using Cronbach's alpha and showed a correlation coefficient of 0.75 , which is within the acceptable range.
The PASS questionnaire consists of two parts. For the current study, the authors used the first part which evaluates university students' procrastination behavior. It focuses on six areas namely, writing a term paper, studying for an exam, keeping up with weekly reading assignments, performing administrative tasks, attending meetings, and performing academic tasks in general. There are eighteen questions and each area consists of three questions. The first question evaluates the frequency of procrastination, the second investigates how much procrastination leads to difficulties and problems in the performance of tasks, and the third question examines the individual's tendency to reduce their procrastination. PASS is a five-point Likert scale from 1 (never procrastinate) to 5 (always procrastinate). According to the scoring system, the higher the score, the higher the level of procrastination.

\section{Data collection and data analysis}

In the last session of the writing class before the final exam, the researchers explained the purpose of the study to the students and how the results could help enhance both learning and teaching. After that, the PASS questionnaire was administered to the students. They were asked to select the appropriate choice for each item from "I never procrastinate" to "I always procrastinate". It took about 20 minutes to read and answer the questionnaire.

The students were asked to compare and contrast the characteristics of two of their close friends based on the comparison and contrast structures the researchers had taught earlier in the class. They were asked to write a 250-word paragraph in 90 minutes. Then, the researchers scored the essay the students wrote in the final exam according to the rubric distributed officially by the English department as shown in Figure 1.

Figure 1

\begin{tabular}{|c|c|c|c|c|c|}
\hline \multirow[t]{2}{*}{ Feature to be evaluated } & \multicolumn{5}{|c|}{ Paragraph 1} \\
\hline & 5 & 4 & 3 & 2 & 1 \\
\hline well narrowed-down and clear topic sentence & & & & & \\
\hline lack of any traces of irrelevant sentences & & & & & \\
\hline lack of any traces of redundancy; unnecessary repetitions; etc. & & & & & \\
\hline sufficiency and effectiveness of support (i.e. in terms of quantity and quality) & & & & & \\
\hline correct use of connecting words/listing signals & & & & & \\
\hline appropriateness and variety of sentence structures & & & & & \\
\hline grammatical accuracy & & & & & \\
\hline appropriateness and richness of vocabulary & & & & & \\
\hline appropriateness of the tone and register (formal, academic, etc.) & & & & & \\
\hline mechanics: indentation, punctuation, capitalization, word endings, legibility, etc. & & & & & \\
\hline general impression & & & & & \\
\hline Total & & & & 50 & \\
\hline
\end{tabular}


The researchers also performed an error analysis based on Dulay et al. (1982) model for the classification of writing errors, one of the most comprehensive models available to date. According to this classification system, errors of omission, addition, misformation, regularization, and misordering as well as archi-forms and alternating forms are divided into four major categories: Interlingual, Ambiguous, Developmental, and Other.

To answer the research questions, descriptive statistics and inferential statistics were used through the application of Statistical Package for Social Sciences (SPSS) version 23. The first research question that asked about the type of errors found in students' essays was answered by using descriptive statistics (mean, standard deviation). The second research question that sought to answer if procrastination correlated with and contributed to the students' writing performance was answered by conducting regression analysis. Finally, the multiple regression analysis was applied to find out if procrastination correlated with and contributed to the types of errors committed by the students, as the third research question.

\section{FINDINGS AND DISCUSSION}

The results of the PASS questionnaire as depicted in Table 1 showed that the students mostly procrastinated in performing academic tasks in general $(95.25 \%)$ followed by keeping up with weekly reading assignments (92.64\%), Attending meetings $(84.53 \%)$, Writing a term paper $(81.25 \%)$, Studying for an exam (78.04\%), and Performing administrative tasks $(74.17 \%)$. The remained percentage to $100 \%$ in each area of the procrastination is related to "never procrastinated" and "nearly never procrastinated" which are not reflected in the following table as we were seeking the procrastination level.

To answer the first research question (What are different types of errors found in students' English writing?), descriptive statistics was applied as reflected in the following Table 2 .

Table 1

Frequency of Students' Procrastination

\begin{tabular}{|c|c|c|c|c|}
\hline Areas of Procrastination & Sometimes & Nearly always & Always & Total \\
\hline Writing a term paper & $20.23 \%$ & $49.11 \%$ & $11.91 \%$ & $81.25 \%$ \\
\hline Studying for an exam & $33.33 \%$ & $41.27 \%$ & $3.44 \%$ & $78.04 \%$ \\
\hline Keeping up with weekly reading assignments & $31.87 \%$ & $53.12 \%$ & $7.65 \%$ & $92.64 \%$ \\
\hline Performing administrative tasks & $28.55 \%$ & $38.21 \%$ & $7.41 \%$ & $74.17 \%$ \\
\hline Attending meetings & $45.73 \%$ & $32.99 \%$ & $5.81 \%$ & $84.53 \%$ \\
\hline Performing academic tasks in general & $30.25 \%$ & $55.86 \%$ & $9.14 \%$ & $95.25 \%$ \\
\hline
\end{tabular}

Table 2

Descriptive Statistics for Different Types of Errors

\begin{tabular}{lccccc}
\hline Type of error & $\begin{array}{c}\text { No. of } \\
\text { respondents }\end{array}$ & $\begin{array}{c}\text { Frequency } \\
\text { of Errors }\end{array}$ & Mean & SD & Rank \\
\hline Developmental & 44 & 297 & 6.75 & 2.08 & 1 \\
Ambiguous & 44 & 202 & 4.59 & 2.01 & 3 \\
Others & 44 & 242 & 5.50 & 2.39 & 2 \\
Interlingual & 44 & 198 & 4.50 & 2.32 & 4 \\
\hline
\end{tabular}

As indicated in Table 2, the most frequently occurred error is Developmental error (mean $=6.75$, $\mathrm{SD}=2.08$ ) followed by Others and Ambiguous errors. Interlingual error was found as the least frequently occurred error (mean $=4.50, \mathrm{SD}=2.32$ ).

Furthermore, the mean score for the students' performance on essay writing was 38.75 out of 50 with a standard deviation of 2.01. The highest score was 47.5 and the lowest score was 20 out of 50 .

To answer the second research question (Does procrastination correlate with and contribute to the students' writing performance?), inferential statistics was applied by the use of regression analysis as indicated in the following table.

Table 3

Regression Analysis between Procrastination and Writing Performance

\begin{tabular}{lcccccc}
\hline Variables & $\mathbf{B}$ & Beta & $\mathbf{T}$ & Sig. T & $\mathbf{R}^{2}$ & Contribution \\
\hline procrastination & -5.60 & -.954 & -20.58 & .000 & .908 & $90.8 \%$ \\
\hline
\end{tabular}

As depicted in Table 3, procrastination was strongly and negatively correlated with the students' writing performance. This can be explained through the power, which can describe the regression model with the value $\left(\mathrm{R}^{2}\right)$, which was .908 . It shows that procrastination correlated with and contributed to the students' writing performance $(\beta=-.954, \mathrm{~T}=$ 20.58 , Sig. $\mathrm{T}=.000$ ) and its contribution was as much as $90.8 \%$. This circumstance showed that when procrastination added up by one unit, the students' writing performance was decreased by .954 units. 
To answer the third research question (does procrastination contribute to types of errors made by the students?), inferential statistics was applied with regression analysis as shown in Table 4.

Table 4

Regression Analysis between Procrastination and Writing Errors

\begin{tabular}{lllllll}
\hline Variables & B & Beta & T & Sig. T & $\mathbf{R}^{2}$ & Contribution \\
\hline Developmental Errors & 2.02 & .355 & 2.46 & .018 & .105 & $10.5 \%$ \\
Ambiguous Errors & 2.39 & .406 & 2.73 & .002 & .225 & $12 \%$ \\
Others Errors & 1.68 & .341 & 2.72 & .000 & .330 & $10.5 \%$ \\
Interlingual Errors & 2.90 & .571 & 5.32 & .000 & .602 & $27.2 \%$
\end{tabular}

The stepwise multiple regression analysis in Table 4 showed that Procrastination had correlation and contribution $(60.2 \%)$ of significance $(p<0.05)$ toward all four types of errors made by the students as the variance value of dependent variable correlated significantly with all independent variables. This can be explained through the power which is able to describe the regression model with the value $\left(\mathrm{R}^{2}\right)$, which was .602. Procrastination mostly contributed to Interlingual errors $(\beta=0.571$, $\mathrm{T}=5.32$, Sig. $\mathrm{T}=.000)$ and its contribution was as much as $27.2 \%$. This circumstance showed that when the level of procrastination added up by one unit, Interlingual errors increased by 0.571 units. After that, students' procrastination contributed to the Ambiguous errors by $12 \%(\beta=0.406, T=2.73$, Sig. $T=.002)$. It means when the level of procrastination added up by one-unit, Ambiguous errors increased by .406 units. As indicated in the table, Procrastination equally $(10.5 \%)$ contributed to Developmental $(\beta=0.355, T=2.46$, Sig. $T=.018)$ and Other $(\beta=0.341, \mathrm{~T}=2.72$, Sig. $\mathrm{T}=.000)$ errors.

In conclusion, when writing English essays, Developmental errors, Others, and Ambiguous errors were some of the most frequent errors to occur among Iranian Medical students. The least frequent errors appeared to be Interlingual. The most frequent errors appeared to be due to the influence of the target language rather than students' first language- in this case, Persian. This may also why the learners might be confused about some grammatical rules in the target language (Kaweera, 2013). There are also some exceptions in the target language, that students might find difficult to learn; they should be able to understand, memorize, and rehearse these in order to learn them. Learning the target language occurs when students make errors. This agrees with the findings presented by Kim (2001) as Interlingual errors, occurring less frequently compared to Developmental errors. This, however, disagrees with what Wu and Graza (2014) represented in their results that Interlingual errors occurred more than Developmental errors since the students relied more on their first language as a strategy while they wrote essays. This may imply that Iranian students in the current study did not find relying on their first language in writing English essays as a good strategy; therefore, they did not resort to first language in writing an English essay, leading to a lower frequency of Interlingual errors.
In addition, based on the findings of this study, procrastination strongly and negatively contributed to the students' writing performance. This finding is congruent with the study done by Bashir and Gupta (2018). They also found a negative relationship in their study, showing that higher academic procrastination led to lower academic performance. Hayat et al. (2020) also found a similar finding. They found out that a high level of procrastination was prevalent among students, leading to low academic achievement and chronic problems in learning. In our study, it was also found that procrastination was prevalent among the students as stated earlier so the students may have developed anxiety due to writing essays (Onwuegbuzie, 2004; Klassen et al., 2008). Writing anxiety negatively affects writing performance and motivation, whereas it positively correlates with academic procrastination (Hartono \& Maharani, 2019).

In addition, students were less interested in writing papers and they did not have a good performance on writing tasks. This aligns with findings based on Fritzsche et al. (2003), as procrastination contributed to delaying of writing tasks and leading to lower grades. They also found that the reason the students procrastinated was due to general anxiety and not receiving feedback on their writing assignments. Moreover, based on a survey done by Lakshminarayan et al. (2013), students showed below-average performance in their academic studies indicating a high level of procrastination. This was due to students' low level of self-esteem and self-efficacy. This may be true for the participants of current study.

Furthermore, in this study, procrastination was found to contribute more to Interlingual and Ambiguous errors while Interlingual errors were the least frequently occurred errors. This may be due to the reason that when the students procrastinate, they try to transfer the language components from their first language to the target language, leading to higher occurrence of such errors. Roxas (2020) stated that grammar and mechanics are important factors as the students have problems in identifying and correcting errors in writing while they may have problems in managing the time as they complete academic writing tasks that might be due to procrastination.

Identification of these errors can provide opportunities for language teachers to develop 
methodology and an approach to creating effective materials for an influential and remedial instruction (Kaweera, 2013). Consequently, the types of errors that language learners make indicate a process of acquitting the target language and this gives a clear learning strategy for each specific individual. Teachers can use this as a tool to learn more about their learners. Finally, the level of procrastination among learners can inform teachers to create strategies such as giving feedback that leads to a motivational and more engaging classroom atmosphere.

More specifically, as the Interlingual errors were the least frequently occurred errors, it shows that the learners' first language, Persian, is not among the remarkable interfering factors in learners' English writing performance. The instructors should mostly focus on English structures and grammar without a remarkable need to discuss and highlight differences between Persian and English for the learners. Although it was found that as the students procrastinate, the occurrence of the Interlingual errors may increase more than the Other errors.

\section{CONCLUSION AND IMPLICATIONS}

The study showed the remarkable correlation between procrastination, writing performance, and writing errors of the students. While the students were found mostly medium to high procrastinators, it was also revealed that their procrastination correlated and contributed more to Interlingual and Ambiguous errors, respectively followed by Developmental and Other errors. In terms of the implications of the present study, some techniques and solutions can be recommended to restrict procrastination. Teachers should encourage the students to write a composition in class time even if it lasts for a very limited time, because homework and classwork can decrease the level of procrastination (Grey, 2017). Working on revisions is something that is forgotten in class time due to time constraints (Berg \& Seeger, 2016) while, according to Grey (2017), working on revisions in class is very effective in restricting procrastination. Moreover, discussing procrastination and using it as a topic in the writing process is also beneficial, which will make the students aware of its negative impacts on learning.

The students may be asked to provide a to-do list to break their writing process to different components including mind mapping, outlining, crafting a stating paragraph vs. writing the entire paper, etc. Active procrastination can also be involved by specifying several deadlines for a specific part of the writing process instead of a deadline for the entire process such as specifying Monday as the deadline for the introduction section instead of a deadline for the entire paper. This can help students to feel the push of a deadline. When a weak system of self-reliance is the reason for procrastination as suggested by psychology-based studies, goal-setting and voluntary activities to achieve tasks are good solutions. The students should be helped to be able to bridge between what they do daily and their goals (Rubin, 2015). Finally, it is recommended to evaluate the effect of taskbased language teaching on procrastination level of the students in writing because task-based language learning is found to be effective in helping students to be active (Kafipour et al., 2018). This may have a role in reducing the procrastination level.

\section{ACKNOWLEDGMENTS}

This paper has been extracted from the approved and funded research project N. 1001 at Shiraz University of Medical Sciences, Shiraz, Iran.

\section{REFERENCES}

Babadoğan, C. (2010). The impact of academic procrastination behaviors of the students in the certificate program in English language teaching on their learning modalities and academic achievements. Procedia-Social and Behavioral Sciences, 2(2), 3263-3269. https://doi.org/10.1016/j.sbspro.2010.03.499

Bashir, L., \& Gupta, S. (2018). A deeper look into the relationship between academic procrastination and academic performance among university students. Online Journal of Multidisciplinary Subjects, 12(3), 531-540.

Berg, M., \& Seeber, B. K. (2016). The slow professor: Challenging the culture of speed in the academy. University of Toronto.

Chow, H. P. H. (2011). Procrastination among undergraduate students: Effects of emotional intelligence, school life, self-evaluation, and self-efficacy. Alberta Journal of Educational Research, 57(2), 234-240.

Dulay, H., Burt, M., \& Krashen, S. (1982). Language two. Oxford University Press.

Ferrari, J. R., O'Callghan, J., \& Newbegin, I. (2005). Prevalence of procrastination in the United States, United Kingdom, and Australia: Arousal and avoidance delays among adults. North American Journal of Psychology, 7(1), 1-6.

Fritzsche, B. A., Young, B. R., \& Hickson, K. C. (2003). Individual differences in academic procrastination tendency and writing success. Personality and Individual Differences, 35(7), 1549-1557. https://doi.org/10.1016/s01918869(02)00369-0

Gray, J. (2017). "It's my closest friend and my most hated enemy": Students share perspectives on procrastination in writing classes. The Journal of Student Success in Writing, 1(1), 4. 
Gropel, P., \& Steel, P. (2008). A mega-trial investigation of goal setting, interest enhancement and energy on procrastination. Personality \& Individual Differences, 45(5), 406-411. https://doi.org/10.1016/j.paid.2008.05.015

Harrington, N. (2005). It's too difficult! Frustration intolerance beliefs and procrastination.

Personality and Individual Differences, 39(5), 873-883. https://doi.org/10.1016/j.paid.2004.12.018

Hartono, H., \& Maharani, M. M. (2019). English writing anxiety and the writing problems of Indonesia EFL learners. Advances in Social Science, Education and Humanities Research, 409, 513-517. https://doi.org/10.2991/assehr.k.200225.111

Hayat, A. A., Jahanian, M., Bazrafcan, L., \& Shokrpour, N. (2020). Prevalence of academic procrastination among medical students and its relationship with their academic achievement. Shiraz E Med, 21(7), 1-7. https://doi.org/10.5812/semj.96049

Ho, M. C. (2016). Exploring writing anxiety and self-efficacy among EFL graduate students in Taiwan. Higher education studies, 6(1), 24-39. https://doi.org/10.5539/hes.v6n1p24

Howell, A. J., Watson, D. C., Powell, R. A., \& Buro, K. (2006). Academic procrastination: The pattern and correlates of behavioural postponement. Personality and Individual Differences, 40(8), 1519-1530.

https://doi.org/10.1016/j.paid.2005.11.023

James, C. (1998). Errors in language learning and use. Longman.

Kafipour, R., Mahmoudi, E., \& Khojasteh, L. (2018). The effect of task-based language teaching on analytic writing in EFL classrooms. Cogent Education, 5(1), 1496627. https://doi.org/10.1080/2331186X.2018.14966 27

Khakpour-Nia, S., \& Shahsavar, Z. (2019). Comparing the use of different prewriting strategies on medical students' 12 Writing. The Asian ESP Journal. 15(2). 228-255.

Kaweera, C. (2013). Writing error: A review of interlingual and intralingual interference in EFL context. English Language Teaching, 6(7), 9-18. https://doi.org/10.5539/elt.v6n7p9

Kim, S. (2001). An error analysis of college students' writing: Is that really Konglish? Studies in Modern Grammar, 25, 159-174.

Kim, S., Fernandez, S., \& Terrier, L. (2017). Procrastination, personality traits, and academic performance: When active and passive procrastination tell a different story. Personality and Individual Differences, 108, 154-157.

https://doi.org/10.1016/j.paid.2016.12.021
Kim, K. R., \& Seo, E. H. (2015). The relationship between procrastination and academic performance: A meta-analysis. Personality and Individual Differences, 82, 26-33. https://doi.org/10.1016/j.paid.2015.02.038

Klassen, R. M., Krawchuk, L. L., \& Rajani, S. (2008). Academic procrastination of undergraduates: Low self-efficacy to selfregulate predicts higher levels of procrastination. Contemporary Educational Psychology, 33(4), 915-931. https://doi.org/10.1016/j.cedpsych.2007.07.001

Kong, B. (2010). Academic procrastination and tolerance of ambiguity among undergraduate and graduate students [Unpublished doctoral dissertation]. Chicago School of Professional Psychology.

Lakshminarayan, N., Potdar, S., \& Reddy, S. G. (2013). Relationship between procrastination and academic performance among a group of undergraduate dental students in India. Journal of Dental Education, 77(4), 524-528. https://doi.org/10.1002/j.00220337.2013.77.4.tb05499.x

O'Brien, W. K. (2002). Applying the transtheoretical model to academic procrastination. ProQuest Information \& Learning.

Onwuegbuzie, A. J. (2004). Academic procrastination and statistics anxiety. Assessment \& Evaluation in Higher Education, 29(1), 3-19. https://doi.org/10.2466/pms.2001.92.2.560

Onwuegbuzie, A. J., \& Collins, K. M. (2001). Writing apprehension and academic procrastination among graduate students. Perceptual and Motor Skills, 92(2), 560-562. https://doi.org/10.3200/socp.149.2.241-257

Ozer, B. U., Demir, A., \& Ferrari, J. R. (2009). Exploring academic procrastination among Turkish students: Possible gender differences in prevalence and reasons. The Journal of Social Psychology, 149(2), 241-257. https://doi.org/10.3200/SOCP.149.2.241-257

Perry, J. (2012). The Art of procrastination: The art of effective dawdling, lollygagging, and postponing. Workman.

Pigg, S. (2014). Emplacing mobile composing habits: A study of academic writing in networked social spaces. College Composition and Communication, 66(2), 250-275.

Roxas, M. J. D. (2020). Exploring senior high school students' academic writing difficulties: Towards an academic writing model. IOER International Multidisciplinary Research Journal, 2(1), 10-19.

Rubin, G. (2015). Better than before: What I learned about making and breaking habits--to sleep more, quit sugar, procrastinate less, and 
generally build a happier life. Broadway Books.

Schouwenburg, H. C. (1995). Procrastination and task avoidance: Theory, research, and treatment. In J. R. Ferrari, J. L. Johnson, \& W. G. McCown (Eds.), Academic procrastination: Theoretical notions, measurement, and research (pp. 71-96). Plenum Press.

Schraw, G., Wadkins, T., \& Olafson, L. (2007). Doing the things we do: A grounded theory of academic procrastination. Journal of Educational Psychology, 99(1), 12. https://doi.org/10.1037/0022-0663.99.1.12

Seo, E. H. (2008). Self-efficacy as a mediator in the relationship between self-oriented perfectionism and academic procrastination. Social Behavior and Personality: An International Journal, 36(6), 753-764. https://doi.org/10.2224/sbp.2008.36.6.753

Shokeen, A. (2018). Procrastination, stress and academic achievement among the B. Ed. students. Educational Quest, 9(1), 125-129.

Solomon, L. J., \& Rothblum, E. D. (1984). Academic procrastination frequency and cognitive behavioral conflates. Journal of Counseling Psychology, 31, 503-509. https://doi.org/10.1037/00220167.31.4.503

Steel, P. (2007). The nature of procrastination: A meta-analytic and theoretical review of quintessential self-regulatory failure.
Psychological Bulletin, 133(1), 65-94. https://doi.org/10.1037/0033-2909.133.1.65

Stewart, M., Stott, T., \& Nuttall, A. M. (2016). Study goals and procrastination tendencies at different stages of the undergraduate degree. Studies in Higher Education, 41(11), 20282043.

https://doi.org/10.1080/03075079.2015.100559 0

Tice, D. M., \& Baumeister, R. F. (1997).

Longitudinal study of procrastination, performance, stress, and health: The costs and benefits of dawdling. Psychological Science, 8(6), 454-458. https://doi.org/10.1111/j.14679280.1997.tb00460.x

Wolters, C. A. (2003). Understanding procrastination from a self-regulated learning perspective. Journal of Educational Psychology, 95(1), 179. https://doi.org/10.1037/0022-0663.95.1.179

Wu, H.-p., \& Garza, E. V. (2014). Types and attributes of English writing errors in the EFL context: A study of error analysis. Journal of Language Teaching \& Research, 5(6), 12561262. https://doi.org/10.4304/jltr.5.6.12561262 